\title{
Effects of cutting parameters on delamination during drilling of Polyphthalamide (PPA) Matrix Composite Material with $30 \%$ Glass Fiber Reinforcement
}

\author{
F. FICICI* Z. AYPARCASI \\ Sakarya University, Faculty of Technology, 54187, Sakarya, Turkey
}

\begin{abstract}
The drilling of glass fiber reinforced plastics (GFRP) often results in damage around the drilled hole. The drilling of such composite material may generate delamination of drilled holes on workpiece. The aim of this research is to investigate the influence of the drilling parameters, such as cutting speed, feed rate and differences in cutting materials on delamination produced while drilling GFRP composite. The experimental results indicate that the feed rate is the most significant factor, followed by spindle speed and cutting tool material. The best results were obtained at lower feed rates and higher spindle speeds when using Carbide drill.
\end{abstract}

DOI: 10.12693/APhysPolA.127.1118

PACS: 81.05.Qk, 81.05.Lg, 81.20.Wk

\section{Introduction}

Glass fibre reinforced plastic (GFRP) composites have widely used engineering application such as automotive, aircraft and manufacture of spaceships and sea vehicles industries due to their significant advantages over other materials. They provide high specific strength/stiffness, superior corrosion resistance, light weight construction, low thermal conductivity, high fatigue strength, ability to char and resistance to chemical and microbiological attacks [1].

In the cutting process, drilling plays a very important role since more than $40 \%$ of material removal processes employ drilling [2]. Traditionally, a drilling tool is made of high speed steel (HSS). Since it generates high temperature during drilling, it causes the tool to dull quicker and leads to a shorter tool life. Moreover, the workpiece hardens easily during drilling, resulting in post-drilling difficulties [3].

Drilling of holes is a very common process in the assembly of composites structures. Surface delamination and fiber pullout are the main quality problems encountered during drilling [4].

Drilling is probably the machining process most widely applied to composites since components made out of composite materials are usually near net shaped, requiring holes for assembly integration. Delamination, which is the major problem associated with drilling fibre reinforced composite materials, reduces the structural integrity of the material, leads to poor assembly tolerances and creates the potential for long-term performance deterioration [5].

This paper investigates the influence of the drilling parameters, such as spindle speed, feed rate and differences

\footnotetext{
*corresponding author; e-mail: fficici@sakarya.edu.tr
}

in cutting tool materials on delamination produced while drilling a PPA matrix composite material with $30 \%$ glass fiber reinforcement.

\section{Experimental procedure \\ 2.1 Drilling tests}

The tests were conducted by drilling in dry cutting conditions on a HAAS TM- 1 three axis CNC milling machine equipped with a maximum spindle speed of $4.000 \mathrm{rpm}$ and a $5.6 \mathrm{~kW}$ drive motor. The $\mathrm{CNC}$ part programs were created by employing Catia $\mathrm{CAD} / \mathrm{CAM}$ software on a personal computer (PC), Intel Pentium IV at $2.8 \mathrm{GHz}$.

Three different material drills have been employed during the drilling tests. Table I shows the detail of the variables used in the experiment. Drills were used in three different cutting speeds at $0.15 \mathrm{~mm} / \mathrm{rev}$ feed rate (Fig. 1).

Experimental details.

TABLE I

\begin{tabular}{c|c}
\hline \hline \multirow{2}{*}{ Workpiece } & $\begin{array}{c}\text { Polyphthalamide (PPA) Matrix } \\
\text { Glass Fiber }\end{array}$ \\
& Fiber volume fraction - 30\% \\
Thickness $-4 \mathrm{~mm}$
\end{tabular}

\subsection{Calculation of delamination factor}

To determine the delamination factor around the holes, the maximum diameter $\left(D_{\max }\right)$ in the delamination zone was measured (Fig. 2). The value of delamination factor $\left(F_{\text {Del }}\right)$ can be determined by the following equation:

$$
F_{D e l}=\frac{D_{\max }}{D_{\text {drill }}}
$$

where $D_{\max }$ is the maximum diameter of the delamination zone in $\mathrm{mm}$ and $D_{\text {drill }}$ is the diameter of the drill in $\mathrm{mm}$. 
HSS

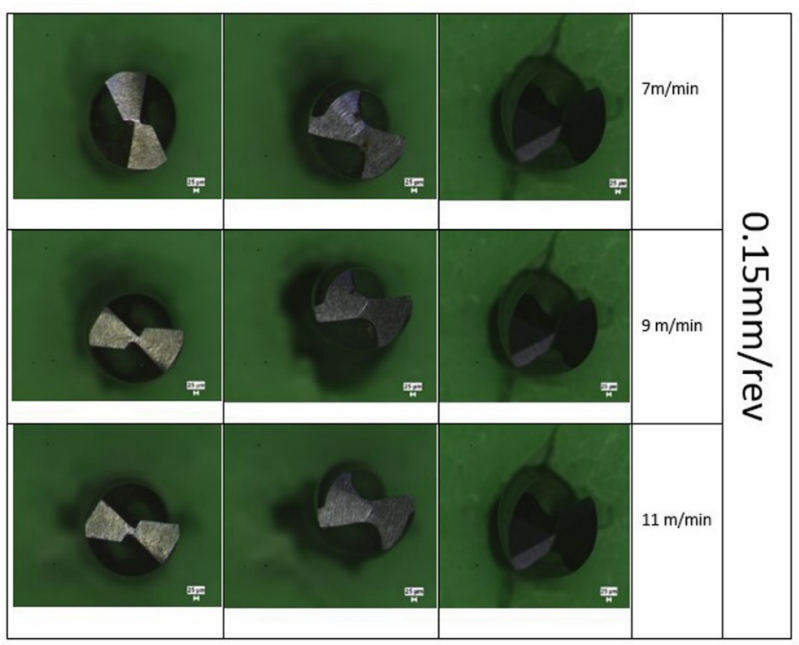

Fig. 1. Drills used in the experimental work.

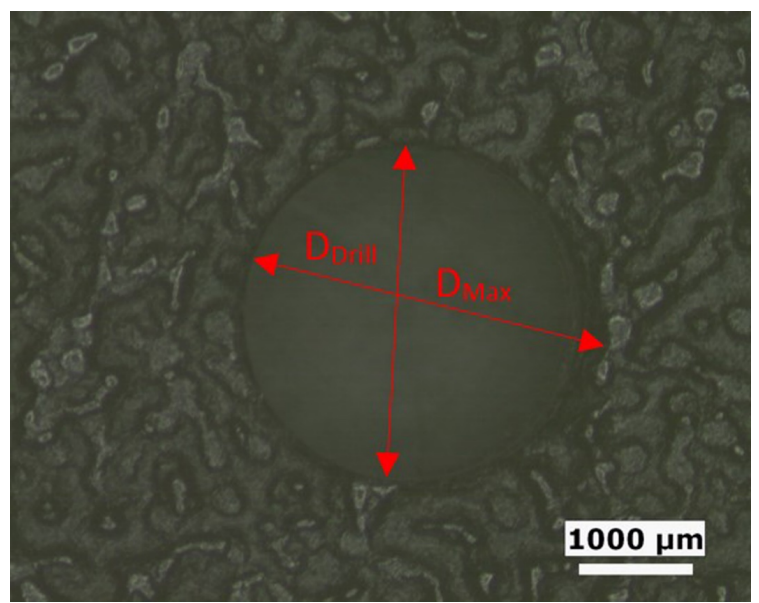

Fig. 2. Photographs illustrating of the delamination factor around the drilled hole using optical microscope.

\section{Results and discussion}

Drilling tests were conducted to evaluate the effects of cutting parameters (cutting speed, feed rate) and differences in cutting tool materials on the damage on workpiece around drilled holes (entrance and exit sides). The damage around the workpiece entrances and exits were measured using a Nikon Eclipse L150 optical microscope. After the measurement of the maximum diameter $D_{\max }$ in the damage around each hole, the delamination factor was determined by utilizing Eq. 1.

Figure 3 and 4 show the effects of drilling parameters on the delamination factor, measured at the drill entrance side of the workpiece. Generally, the delamination factor increases with increases in the feed rate but decreases with increases in the spindle speed Also, under the highest spindle speed $(11 \mathrm{~m} / \mathrm{min})$ cutting condition, the delamination factor seems to be less sensitive to the feed rate. This behaviour may be explained by the cutting temperature. At lower spindle speeds lower

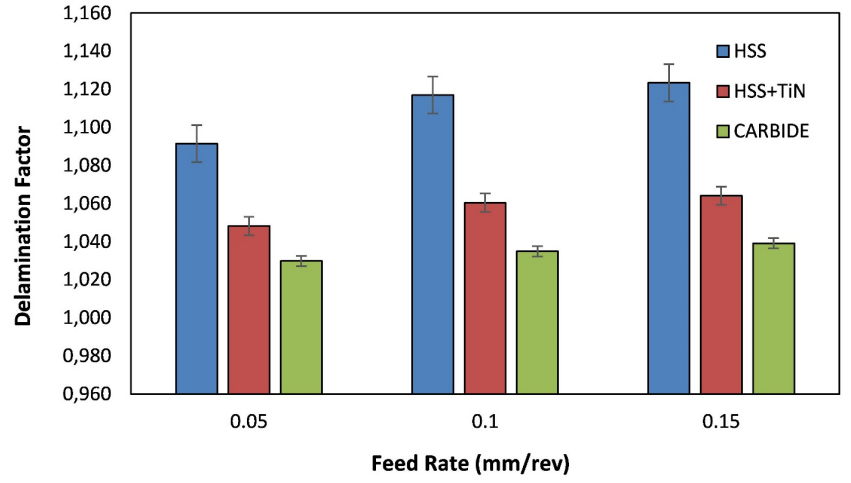

Fig. 3. The effect of feed rate on the delamination factor at $7 \mathrm{~m} / \mathrm{min}$ spindle speed.

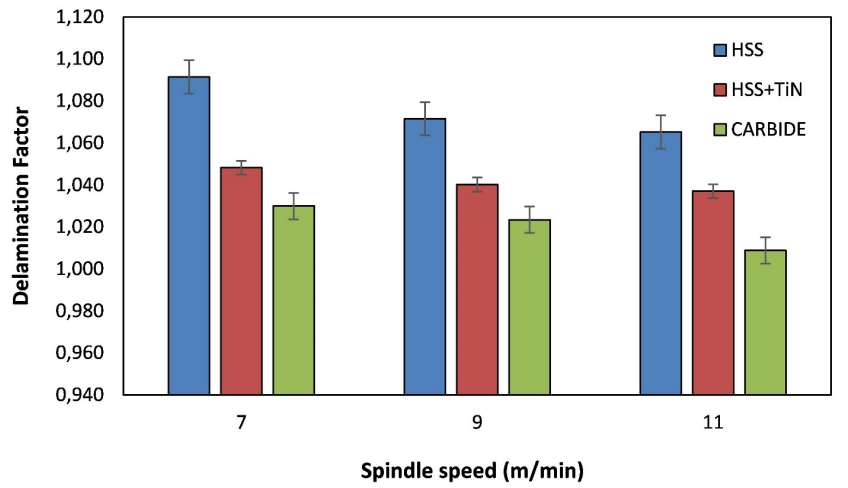

Fig. 4. The effect of spindle speed on the delamination factor at $0.05 \mathrm{~mm} / \mathrm{rev}$ feed rate.

temperatures are observed and delamination takes place as a result of the stresses imposed by shearing. However, at a spindle speed of $11 \mathrm{~m} / \mathrm{min}$ the heat generated by friction between the major and minor cutting edges and the work material induces softening of the matrix. The results presented are in correlation with the results presented by Palanikumar et al. [6] where glass fiber reinforced epoxy composite was used as workpiece material.

Comparison of the effects of the three different drill materials tested shows that the HSS twist drill provides higher delamination factor values (see Fig. 4). The carbide drill gave the best results. The second best results were obtained by coated HSS+TiN drill. These findings indicate that for the tool materials and cutting parameters tested, there is a straightforward relationship between drilling parameters and delamination as suggested by $[7,8]$ similar results were also mentioned by various researchers Abrao et al. [9]; Rajamurugan et al. [10].

\section{Conclusions}

The following conclusions can be drawn, based on this study:

1) The experimental results show that the delamination factor increases with increases in the feed rate.

2) The delamination factor decreases with increases in the spindle speed. 
3) The best results are given by Carbide drill.

4) Appropriate selection of cutting parameters improves the performance in drilling process.

\section{Acknowledgments}

The authors wish to thank to Sakarya University Scientific Research Foundation (Project number: (2014-5001-019) for their support.

\section{References}

[1] E. Kilickap, Expert Syst. Appl. 37, 6112 (2010).

[2] E. Brinksmeier, Ann. CIRP 39, 97 (1990).

[3] H.M. Chow, S.M. Lee, L.D. Yang, J. Mater. Process Techn. 207, 180 (2008).
[4] J.P. Davim, P. Reis, Mater. Design 24, 315 (2003).

[5] I. El-Sonbaty, U.A. Khashaba, T. Machaly, Compos. Struct. 63, 329 (2004).

[6] K. Palanikumar, B. Latha, V. Senthilkumar, J.P. Davim, Mater. Manuf. Process 27, 297 (2012).

[7] NS. Mohan, SM. Kulkarni, A. Ramachandra, Mater. Proc. Technol. 186, 186 (2007).

[8] K. Palanikumar, S. Prakash, K. Shanmugam, Mater. Manuf. Process. 8, 858 (2008).

[9] A.M. Abrao, J.C. Campos Rubio, P.E. Faria, J.P. Davim, Mater. Design 29, 508 (2008).

[10] T.V. Rajamurugan, K. Shanmugam, K. Palanikumar, Mater. Design 45, 80 (2013). 